\title{
Computed tomography-based tissue-engineered scaffolds in craniomaxillofacial surgery
}

\author{
M. H. Smith ${ }^{1 *}$ \\ C. L. Flanagan ${ }^{2}$ \\ J. M. Kemppainen ${ }^{2}$ \\ J. A. Sack $^{2}$ \\ H. Chung ${ }^{2}$ \\ S. $\operatorname{Das}^{2}$ \\ S. J. Hollister ${ }^{2}$ \\ S. E. Feinberg ${ }^{1}$ \\ ${ }^{1}$ Department of Surgery, Division of \\ Oral and Maxillofacial Surgery, \\ University of Michigan, Ann Arbor, \\ MI, USA \\ ${ }^{2}$ College of Engineering, Departments \\ of Biomedical Engineering and \\ Mechanical Engineering, University of \\ Michigan, Ann Arbor, MI, USA \\ *Correspondence to: M. H. Smith, \\ Department of Surgery, Division of \\ Oral and Maxillofacial Surgery, \\ 1500 E. Medical Center Dr., TC \\ B1-208, Ann Arbor, MI 48109-0018, \\ USA. E-mail: milsmith@umich.edu
}

Accepted: 20 May 2007

\begin{abstract}
Introduction Tissue engineering provides an alternative modality allowing for decreased morbidity of donor site grafting and decreased rejection of less compatible alloplastic tissues.
\end{abstract}

Methods Using image-based design and computer software, a precisely sized and shaped scaffold for osseous tissue regeneration can be created via selective laser sintering. Polycaprolactone has been used to create a condylar ramus unit (CRU) scaffold for application in temporomandibular joint reconstruction in a Yucatan minipig animal model. Following sacrifice, micro-computed tomography and histology was used to demonstrate the efficacy of this particular scaffold design.

Results A proof-of-concept surgery has demonstrated cartilaginous tissue regeneration along the articulating surface with exuberant osseous tissue formation. Bone volumes and tissue mineral density at both the 1 and 3 month time points demonstrated significant new bone growth interior and exterior to the scaffold.

Conclusion Computationally designed scaffolds can support masticatory function in a large animal model as well as both osseous and cartilage regeneration. Our group is continuing to evaluate multiple implant designs in both young and mature Yucatan minipig animals. Copyright (c) 2007 John Wiley \& Sons, Ltd.

Keywords Tissue Engineering; Scaffold; Polycaprolactone; Temporomandibular joint; image based design; bone regeneration

\section{Introduction}

Surgeons are forever searching for improved techniques for reconstruction. Surgically removed pathology, traumatic lesions, degenerative changes and infectious conditions can all result in significant soft- and hardtissue defects. Over the years, autogenous bone has remained the gold standard for maxillofacial reconstruction (1-5). Distraction osteogenesis has also been attempted but is inconvenient, due to a longer treatment time, failure of the device and need for further procedures (6-8). Prepared allogeneic tissues can also be used; however, patients run the risk of disease transmission, inflammation and ultimately rejection (9). More recently, biologically inert alloplastic materials offer a reasonable alternative $(2,4)$; however, these materials are not bioresorbable and pose continued risks of inflammation and possible infection $(2,4,10,11)$. 
Tissue engineering (TE) is continuing to evolve, offering new techniques and biocompatible materials to recapitulate the facial skeleton. An ideal tissue-engineered product would achieve a number of goals to be considered effective (12-15). First, it must regenerate complex threedimensional (3D) anatomical defects, while possessing mechanical properties similar to the native structures, allowing for function and possible immediate load bearing, while at the same time preventing stress shielding through material tissue stiffness mismatch. Second, the materials used must be biocompatible and, ideally, bioresorbable, to avoid significant tissue response by either rejection through an immunological response or foreign body reaction through an inflammatory response. Third, it must contain continuous internal porosity for proper tissue formation, and nutrient and waste exchange, while discouraging excess tissue growth and harmful fibrous tissue ingrowth. Last, it should encourage appropriate cell differentiation through either soluble or insoluble factor signalling and/or allow for delivery of pluripotent cell types, such as cells derived from patient bone marrow (12-16). These soluble or insoluble signals are variable, depending upon the application, but may include growth factors and other proteins, gene therapy vectors, surface modifications affecting cell attachment and differentiation, and the physical properties of the scaffold microstructure itself (mechanosignalling, micropatterning) $(12,17)$. By providing a construct to fill the defect, cells from surrounding tissues or delivered cells grow within an enriched environment, the regenerated tissues remodel and the scaffold itself slowly degrades. An optimal degradation pattern allows for maturation of regenerated tissues to support the mechanical load at the same rate that the scaffold gives up its mechanical support $(12,16,18,19)$.

\section{Computer-Based Applications in Tissue Engineering}

\section{Image-based design}

Recently, the use of computed tomography (CT) and magnetic resonance imaging (MRI) has extended beyond the diagnosis of disease processes to their use as a dataset for TE applications (12,14,20-22). One clear advantage of using these datasets is to create a 3D surgical model $(23,24)$. More recently they have been applied to defining specific anatomical geometries for TE scaffold creation.

In regions of defects or abnormal anatomy, a template can be produced using a mirrored image of the contralateral side to recreate normal anatomy. If the desired outcome is to fill in a defect space precisely, a template can be created using image-processing techniques to select and define the defect area from the CT/MRI data. Scaffolds can be designed from these imaging templates by adjusting grey-scale density distribution within a voxel dataset. A structured voxel dataset is a regular cubic grid containing volume elements called voxels. These voxels have a grey-scale density range of 0-255 when using an eight-bit representation of data. On the global anatomical level, a mapping dataset can be created by defining a threshold density level between 0 and 255, where any voxels having density above the threshold level are considered to be material in the scaffold, while voxels below the threshold are considered to be void $(14,21,22,25)$.

Once the mapping dataset is created at the global anatomical level, a porous architecture database is designed on a microstructural level. Criteria and optimization algorithms for designing the porous architecture have been detailed elsewhere $(14,21,25-27)$. A variety of individual porous architecture designs can be used within a single scaffold by creating local image databases (28). For example, these local image databases can be combined to produce a heterogeneous internal structure within the scaffold, allowing for variations in porous microstructure that may create region-specific changes in properties, such as modulus, permeability and pore shape $(14,21,25,29)$. In general, the porous architecture is designed to give desired mechanical and mass transport properties, taking into account the base properties of the scaffold biomaterial. By providing high porosity to increase biofactor delivery, one runs the risk of reducing strength (elastic modulus and yield strength) of the scaffold. The ideal is to design a scaffold, paying attention to the intrinsic properties of the biodegradable material to be used, that provides a high porosity for nutrient and metabolic waste exchange while being able to withstand mechanical load and function in the desired anatomical location $(14,16,19,21,25,26,28,29)$.

\section{Scaffold fabrication}

Scaffolds themselves have been created by a variety of methods, using a variety of biomaterials, including polymers, ceramics and composites. Biodegradable polymers include polylactic acid, polyglycolic acid, polypropylene fumarate and polycaprolactone (16,30-38). Ceramics such as hydroxyapatite and tricalcium phosphate are used but degrade minimally over time $(6,14,39)$. Composite scaffolds may include any combination of polymers, ceramics, metals and biofactors, and attempt to maximize tissue regeneration within the scaffold $(12,16,17,19,29,40-46)$.

Conventional fabrication methods include salt leaching, solvent casting, the use of fibre-based fabrics, thermal phase separation, melt moulding, membrane lamination, templating, fluid-gassing and emulsion freeze-drying $(47,48)$. Major fallbacks include the use of toxic organic solvents during the manufacturing process, less predictable external and internal geometries, and extreme technique sensitivity. In order to circumvent these limitations, the use of solid free-form fabrication (SFF) in tissue engineering was established. SFF is a technique that allows the precise fabrication of complex 3D anatomical 
scaffolds created by computer-generated image-based design techniques, using a layer-by-layer manufacturing approach (12,47,49-51). Techniques include fused deposition modelling, 3D printing, stereolithography, inkjet printing and selective laser sintering (SLS).

SLS uses a laser to provide thermal energy to sinter particles together without causing degradation to the underlying chemical composition. Layer by layer, sequential films of powder are deposited onto the bed, while the laser and radiant heaters selectively coalesce particles of powder through the application of thermal energy, causing an overall release of surface free energy (Figure 1). The subsequent layer will fuse with the underlying layer within the bed of surrounding loose powder.

Our primary focus has been evaluating SLS fabricated polycaprolactone (PCL) scaffolds for TE applications. PCL is a well-characterized, biocompatible, bioresorbable polymer that has been approved for human use by the United States Food and Drug Administration (www.fda.gov). It possesses a number of desired characteristics for use in TE. It has been documented as having an approximate in vivo degradation time of approximately 2 years (52). PCL powder marketed under CAPA ${ }^{\circledR} 6501$ (Solvay Caprolactones, Warrington, UK) possesses a semi-crystalline structure, with $99 \%$ of the particles measuring less than $100 \mu \mathrm{m}$. Its melting point is $58-60^{\circ} \mathrm{C}$, with a decomposition temperature of $350^{\circ} \mathrm{C}$. It can also be processed with other polymers, such as polylactic and polyglycolic acids (52). In solid cylindrical form, PCL created using SLS possesses a compressive modulus of $122 \mathrm{MPa}$ and a compressive strength of 11.7 MPa. These values are on the lower end of human mandibular trabecular bone in the region of the condyle. SLS scaffolds with $50 \%$ porosity demonstrate a compressive modulus of $55 \mathrm{MPa}$ and a compressive strength of $2.3 \mathrm{MPa}(12,53)$.

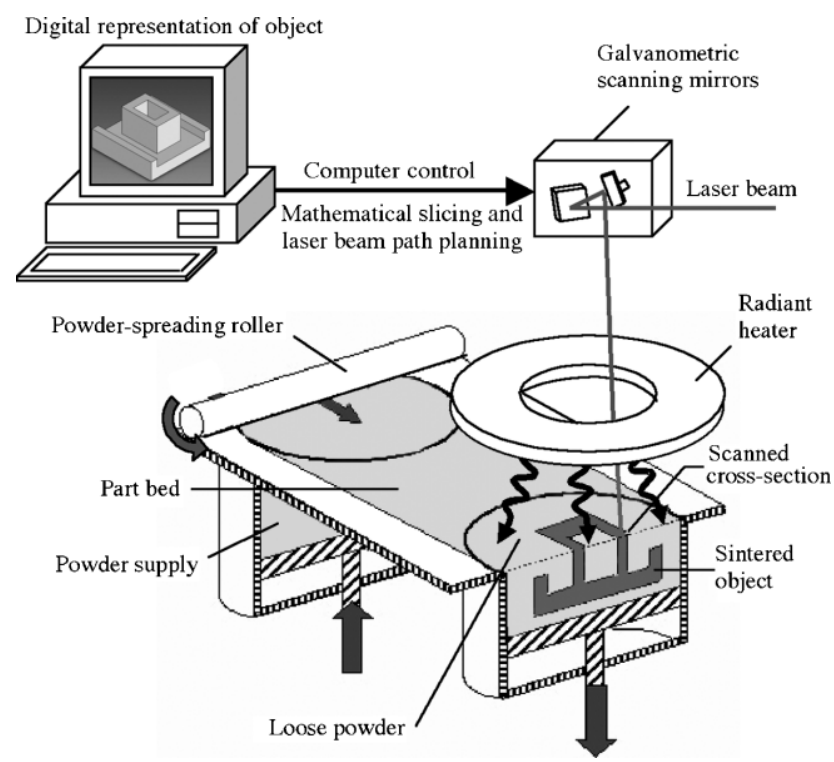

Figure 1. Solid free-form fabrication - selective laser sintering process schematic
Specifically, we have investigated the manufacture of a computer-designed scaffold for temporomandibular joint replacement. Using a Yucatan minipig animal model, we have created a condylar ramus unit (CRU) scaffold. Condylectomies were performed in both young and mature age groups, although we are now focusing on the mature animal model, as there exists a restricted growth potential that will more appropriately relate to human populations.

\section{Methods}

The first step in creating the CRU scaffold was segmentation of the condyle shape from a representative CT scan of both a young and a mature minipig mandible. The image dataset was read using a variety of commercial software, including ANALYSE ${ }^{\mathrm{TM}}$ (www.analysedirect.com), Interactive Data Language (IDL; www.ittvis.com) and MATLAB (www.mathworks.com). A means to surgically fix the scaffold to the ramus was added by creating a collar with screw holes that would fit around the mandibular ramus (post-condylectomy). The collar was created by performing image dilatation of the ramus in the inferior-superior direction (Figure 2A). The dilatation essentially expands the structure outward from the ramus. Finally, the condylar head region of the scaffold image is created with two different density values to allow mapping of a designed porous architecture (Figure 2B).

For the current application (prototype surgery), a shell configuration for replacement of the condylar head was developed, in order to evaluate overall growth potential of osseous and cartilaginous tissues within the confines of a biodegradable scaffold. In additional surgeries, we are comparing the use of orthogonal

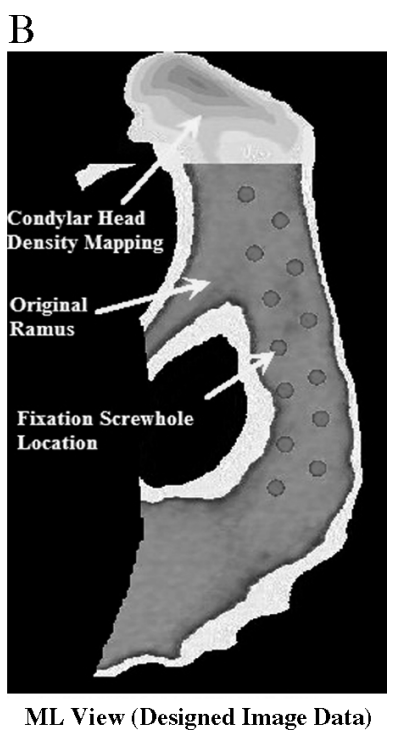

Figure 2. Example of image-based design for condyle scaffold from CT scan. (A) Dilatation of original segmented condylar head slice to create scaffold fixation collar. (B) Slice of designed image data showing condylar head mapping data, original ramus and designed screwholes 


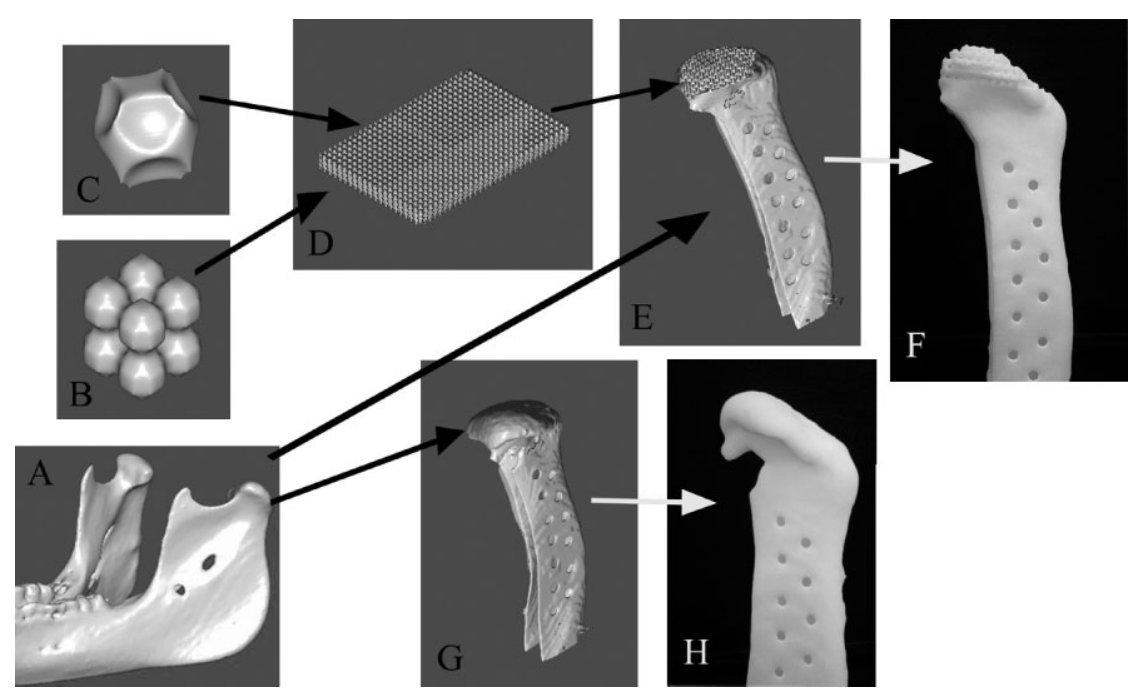

Figure 3. Example of image-based design procedure for mandibular condyle scaffold. (A) CT scan of Yucatan minipig condyle used to design external anatomical shape and surgical fixation. (B-D) Porous architecture databases based on geometrical equations for bone and cartilage region. (E) Final integrated image design of mandibular condyle scaffold with external anatomical shape, surgical fixation, and interior designed porous architecture. (F) Mandibular condyle scaffold architecture design fabricated from polycaprolactone, a degradable biopolymer. (G) Final image design of mandibular condyle scaffold, demonstrating anatomical shape, surgical fixation and shell condylar region. (H) Mandibular condyle scaffold shell design fabricated from polycaprolactone

channel architecture with a spherical void in an attempt to enhance cartilage matrix formation. Results of these studies are pending. Figure 3 illustrates the entire imagebased scaffold design procedure from CT scan through to final fabricated scaffold. Figure 4 demonstrates a higherresolution image of the scaffold design, with orthogonal strut architecture engineered to the specific dimensions of the condylar head and the cross-section of the dilated ramus sleeve.

Using PCL (CAPA ${ }^{\circledR}$ 6501), a CRU scaffold for a young Yucatan minipig (Lone Star Swine, Seguin, TX, USA) was fabricated with SLS. Our SLS system uses a lowpower $\mathrm{CO}_{2}$ laser $(\lambda 10.6 \mu \mathrm{m}$, continuous wave, power $<10 \mathrm{~W}$ ) focused to a $450 \mu \mathrm{m}$ spot (Sinterstation 2000, a commercial SLS machine; 3D Systems Inc., Valencia, CA, USA) $(9,54)$.
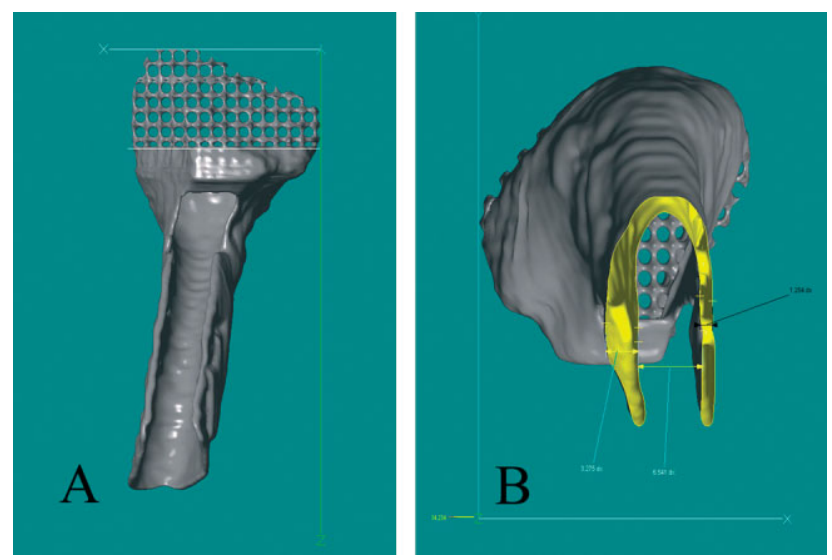

Figure 4. High-resolution depictions of image-based designed CRU. (A) Precisely engineered orthogonal strut architecture replacing condylar head of minipig mandible. (B) Dilated mandibular ramus sleeve in cross-section (yellow)
With approval of the University of Michigan animal ethics committee (UCUCA; www.ucuca.umich.edu), our prototype surgery involved placement of a shell CRU scaffold into five young animals (aged 6-8 months). The animals were anaesthetized and a horizontal condylectomy was performed, as demonstrated in Figure 5. The condylar head of the CRU was then packed with iliac crest bone marrow harvested from each animal, and the fitted CRU scaffold sleeve was inserted over the mandibular ramus. The condylar head closely reapproximated the vertical dimension and volume of the condylectomy segment and provided a new articular surface for the minipig to function with. The CRU was then secured using miniplates and screws (KLS Martin, Jacksonville, FL, USA; Figure 6). The contralateral temporomandibular joint (TMJ) was left intact as a control.

Following a postoperative period of either 1 or 3 months, the animals were sacrificed. The condyles and their opposing articular eminence of both the treated and control sides were sectioned en bloc (articular eminence, articular disc, CRU scaffold and surrounding mandible) for further evaluation.

\section{Micro-CT}

The harvested specimens were imaged in water using micro-computed tomography (micro-CT; GE Healthcare Explore MS-130 scanner with a $20-130 \mathrm{kVp}, 0-500 \mathrm{~mA}$, micro-focus cone beam X-ray source: London, $\mathrm{ON}$, Canada; www.gehealthcare.com). The system settings were $75 \mathrm{kVp}$ and $75 \mathrm{~mA}$, and data were acquired with an isotropic voxel size of $45 \mu \mathrm{m}$. Houndsfield unit calibration was performed with a phantom containing water, air and cortical bone mimic. Using a Feldkamp cone beam 


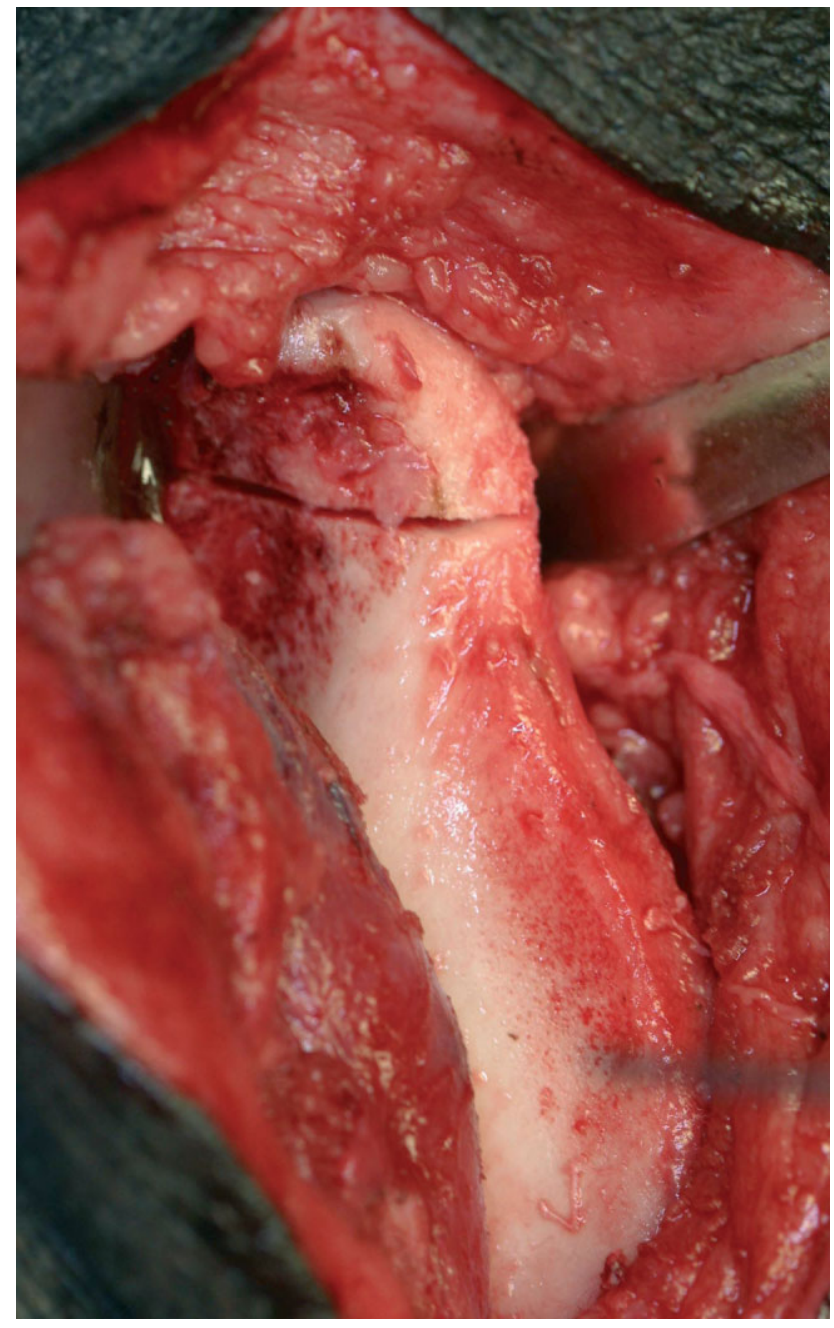

Figure 5. Horizontal condylectomy of mandibular condyle

reconstruction algorithm (55), a 3D representation of the material scanned was used to evaluate for growth of new bone, both within and external to the scaffold. The data were reorientated in Microview 2.1.2 software (www.microview.sourceforge.net) with the Visualization Plus plug-in (GE Healthcare, London, ON, Canada) to identify the ostectomy plane relative to bony landmarks and fixation screw positions. Using a uniform threshold value, new bone volume was determined. The isolation of desired areas was achieved by defining a specified region of interest (ROI), using the Advanced ROI plugin and the spline tool. Tissue mineral density and content, indicators of the quality of newly formed osseous tissue, were calculated for each ROI. Condylectomy pieces above the sectioned mandible at the time of initial surgery, from a representative group of young minipigs, were also subjected to micro-CT for bone volume quantification.

\section{Histology}

The specimens were then decalcified, paraffin-embedded and sectioned $(10 \mu \mathrm{m})$ for histological analysis of the regenerated joint structure and surface. Histological staining was performed using haematoxylin and eosin (H\&E) to evaluate bone regeneration and architecture within and external to the scaffold. Fast green/safranin O stain was utilized for demonstration of cartilaginous tissue formation, with focus along the joint surface.

Table 1. Bone volume and tissue mineral density of condylectomy control segments from six young Yucatan minipigs

\begin{tabular}{lcc}
\hline $\begin{array}{l}\text { Controls (six young } \\
\text { minipigs) }\end{array}$ & BV $\left(\mathrm{mm}^{3}\right)$ & TMD $(\mathrm{mg} / \mathrm{cc})$ \\
\hline Ave & 1524.2 & 477.3 \\
SD & 337.8 & 17.1 \\
\hline
\end{tabular}

$\mathrm{BV}$, bone volume; TMD, tissue mineral density

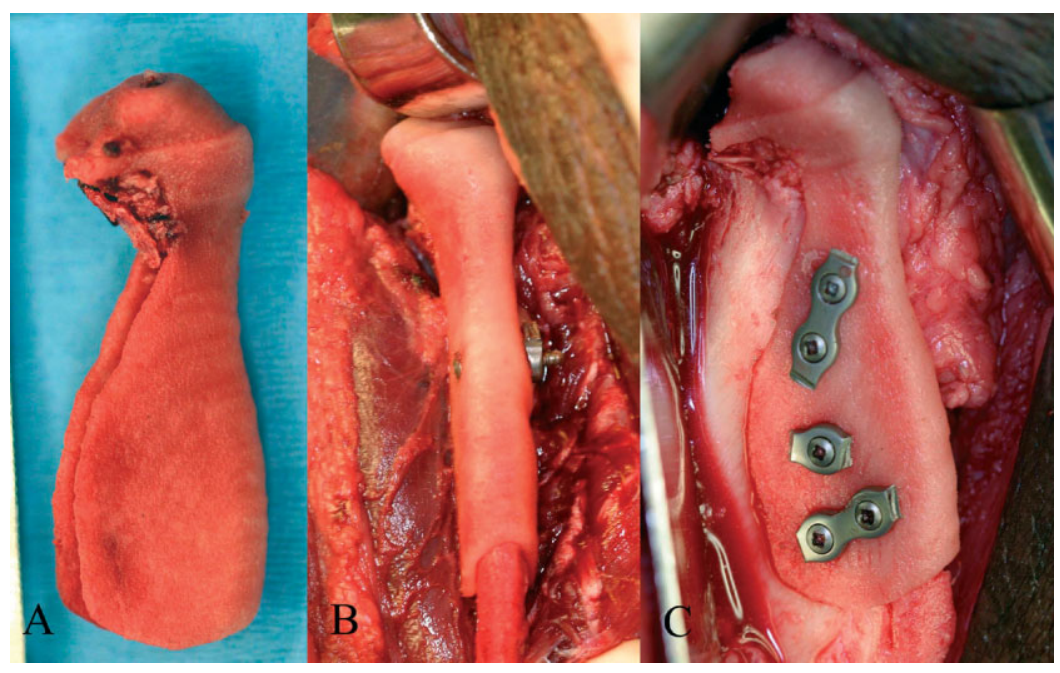

Figure 6. (A) Iliac crest bone marrow packed into scaffold condylar head. (B) Scaffold well adapted to native mandible. (C) Scaffold secured to ramus 
Table 2. Bone volume and tissue mineral density regenerated above the condylectomy line at both 1 and 3 month time points

\begin{tabular}{|c|c|c|c|c|c|c|c|}
\hline & & \multicolumn{2}{|c|}{ Total new bone } & \multicolumn{2}{|c|}{$\begin{array}{c}\text { New bone external to } \\
\text { implant }\end{array}$} & \multicolumn{2}{|c|}{$\begin{array}{c}\text { New bone internal to } \\
\text { implant }\end{array}$} \\
\hline & & $\mathrm{BV}\left(\mathrm{mm}^{3}\right)$ & $\mathrm{TMD}(\mathrm{mg} / \mathrm{cc})$ & $\mathrm{BV}\left(\mathrm{mm}^{3}\right)$ & $\mathrm{TMD}(\mathrm{mg} / \mathrm{cc})$ & $\mathrm{BV}\left(\mathrm{mm}^{3}\right)$ & $\mathrm{TMD}(\mathrm{mg} / \mathrm{cc})$ \\
\hline \multirow[t]{4}{*}{ Shell, 1 month } & Pig 1 & 1221.81 & 549.5 & 829.2 & 589.0 & 392.9 & 466.0 \\
\hline & Pig 2 & 1425.36 & 462.8 & 1167.5 & 463.4 & 541.0 & 460.4 \\
\hline & Ave & 1323.6 & 506.1 & 998.4 & 526.2 & 325.3 & 463.2 \\
\hline & SD & 143.9 & 61.2 & 239.3 & 88.8 & 95.5 & 4.0 \\
\hline \multirow[t]{4}{*}{ Shell, 3 months } & Pig 3 & 4634.32 & 588.4 & 3347.1 & 568.6 & 1287.2 & 639.7 \\
\hline & Pig 4 & 5455.60 & 572.6 & 4409.8 & 565.9 & 1045.8 & 600.5 \\
\hline & Ave & 5045.0 & 580.5 & 3878.5 & 567.3 & 1166.5 & 620.1 \\
\hline & SD & 580.7 & 11.2 & 751.5 & 1.9 & 170.8 & 27.7 \\
\hline
\end{tabular}

BV, bone volume; TMD, tissue mineral density.

\section{Results}

All five of the animals returned to full masticatory function. Micro-CT data was obtained for condylectomy segments of six Yucatan minipigs for control (Table 1).

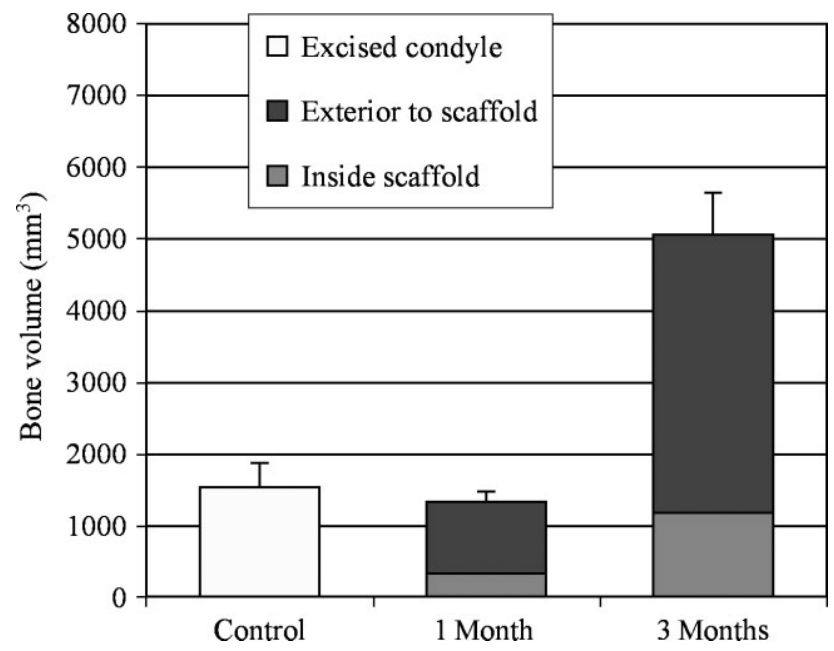

Figure 7. Total bone volume of treatment groups compared to controls

A

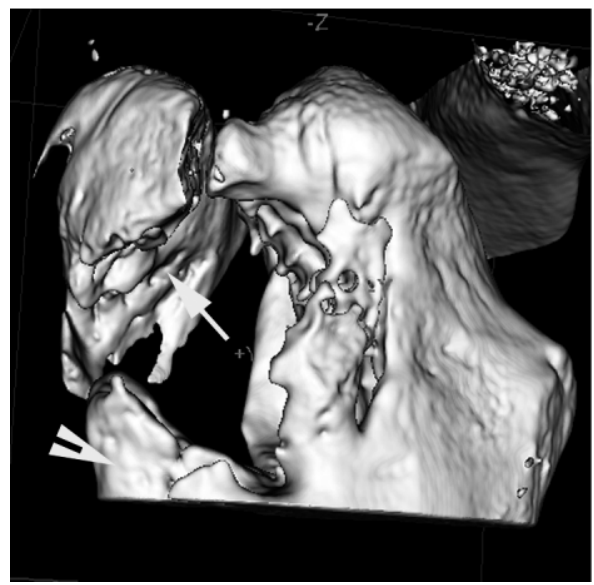

Micro-CT data of bone volume and tissue mineral density demonstrated evidence of new bone growth within the implanted scaffold in four of the five animals (Table 2). One animal was noted to have an infection that was treated prior to sacrifice. Although bone was formed outside the scaffold, this young minipig did not regenerate mineralized tissues within the scaffold,

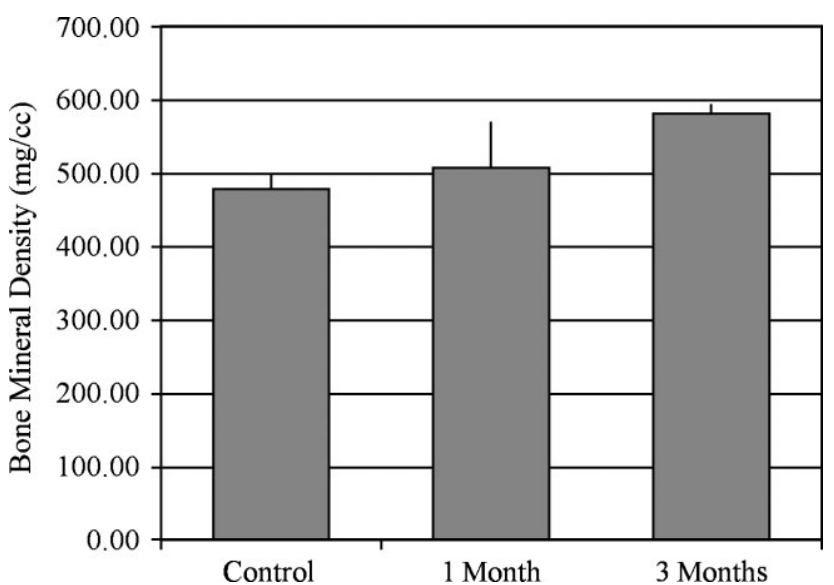

Figure 8. Tissue mineral density of control group vs. treatment groups

B

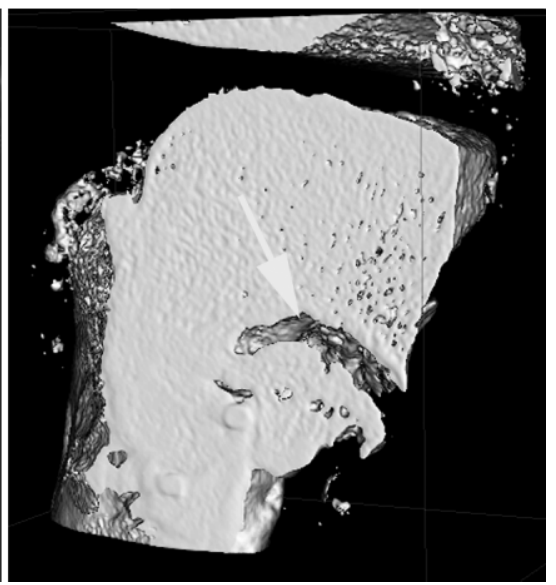

Figure 9. 3D micro-CT images. (A) Exuberant bone tissue formation adjacent to native zygomatic arch (arrow) and coronoid process (arrowhead). (B) large amount of bone tissue formed external to scaffold (void highlighted by arrow) 


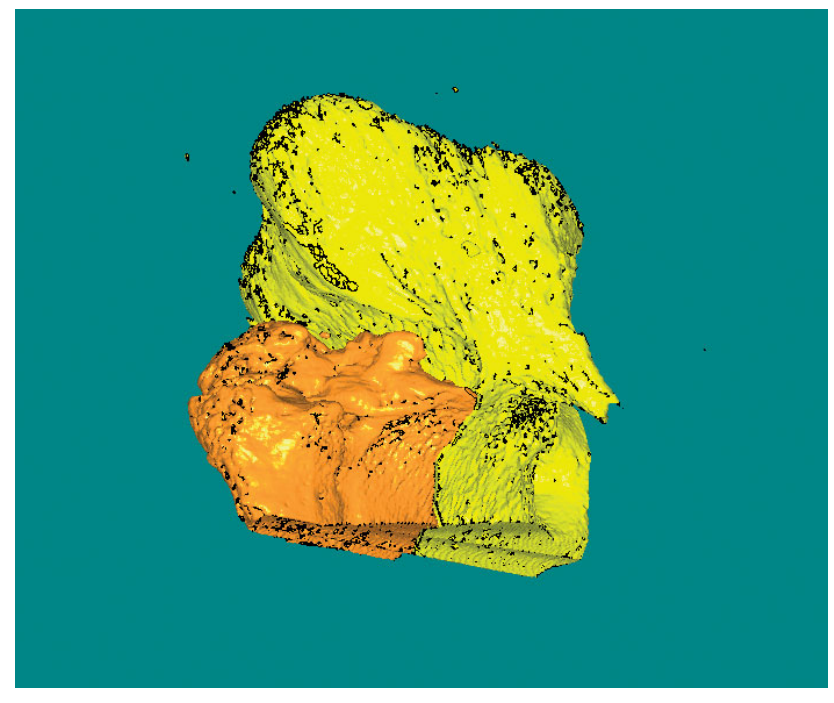

Figure 10. 3D micro-CT volume dataset image. Bone formation above condylectomy cut is depicted within scaffold (orange) and external to scaffold (yellow)

therefore the results are not included in the analysis. At the 1 month time point, total bone volume (treatment group, $n=2,1323.6 \pm 143.9 \mathrm{~mm}^{3}$; control group, $n=6,1524.2 \pm 337.8 \mathrm{~mm}^{3}$ ) and tissue mineral density (treatment group, $506.1 \pm 61.2 \mathrm{mg} / \mathrm{cc}$; control group, $477.3 \pm 17.1 \mathrm{mg} / \mathrm{cc}$ ) were comparable to controls. At the 3 month time point, total bone volume (treatment group, $n=2,5045.0 \pm 580.7 \mathrm{~mm}^{3}$ ) and tissue mineral density (treatment group, $n=2,580.5 \pm 11.2$ ) were substantially increased. It was notable that there was a large amount

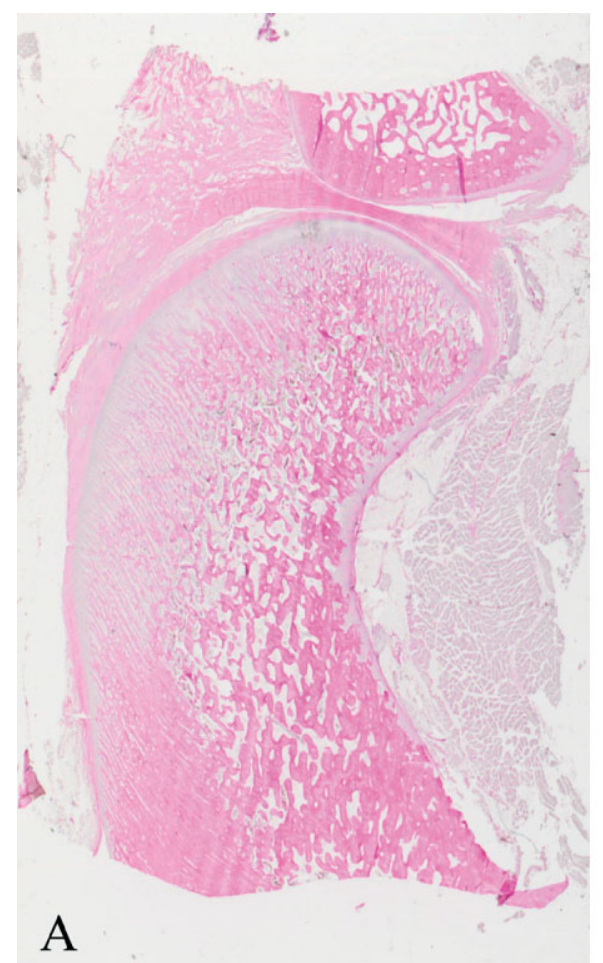

of bone evident external to the confines of the scaffold in both the 1 and 3 month treatment groups. The bone volume within the scaffold closely reapproximated the control condylectomy segments at 3 months (Figure 7). Overall tissue mineral density also closely approximated controls in both treatment groups (Figure 8). Figures 9 and 10 demonstrate 3D images of bone growth. Histological analysis demonstrates normal osseous architecture both internal and external to the scaffold compared to contralateral control temporomandibular joints in the same animal (Figures 11, 12). Cartilaginous tissue formation is clearly evident along the articular surface in the young animals at both the 1 and 3 month time points (Figure 13).

\section{Discussion}

The surgeries described show promising results for the application of tissue engineering in temporomandibular reconstruction. Using bone volume quantification from the micro-CT datasets, the young animal model clearly demonstrated an exuberant amount of osseous tissue using a biodegradable tissue-engineered scaffold, possibly due to its innate healing response. Along with the formation of osseous tissues, histology displayed the production of cartilaginous tissues on the articular surfaces of the regenerated condyles.

Image-based design techniques provide two important advantages for scaffold design $(14,21)$. First, imagebased design techniques are directly compatible with

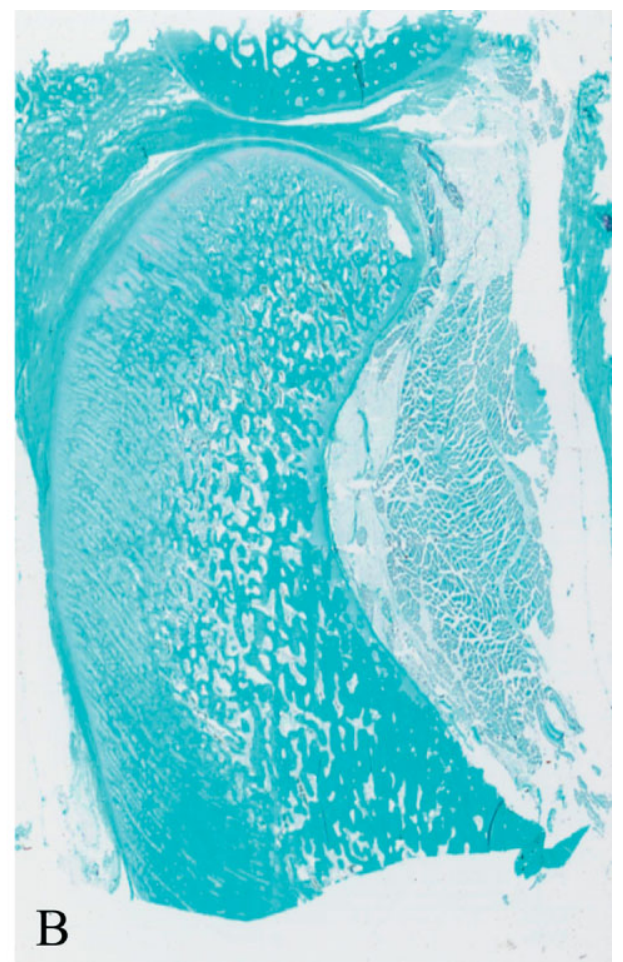

Figure 11. Normal temporomandibular joints in the young Yucatan minipig. Contralateral control joints with (A) H\&E, (B) safranin $\mathrm{O} /$ fast green stains 


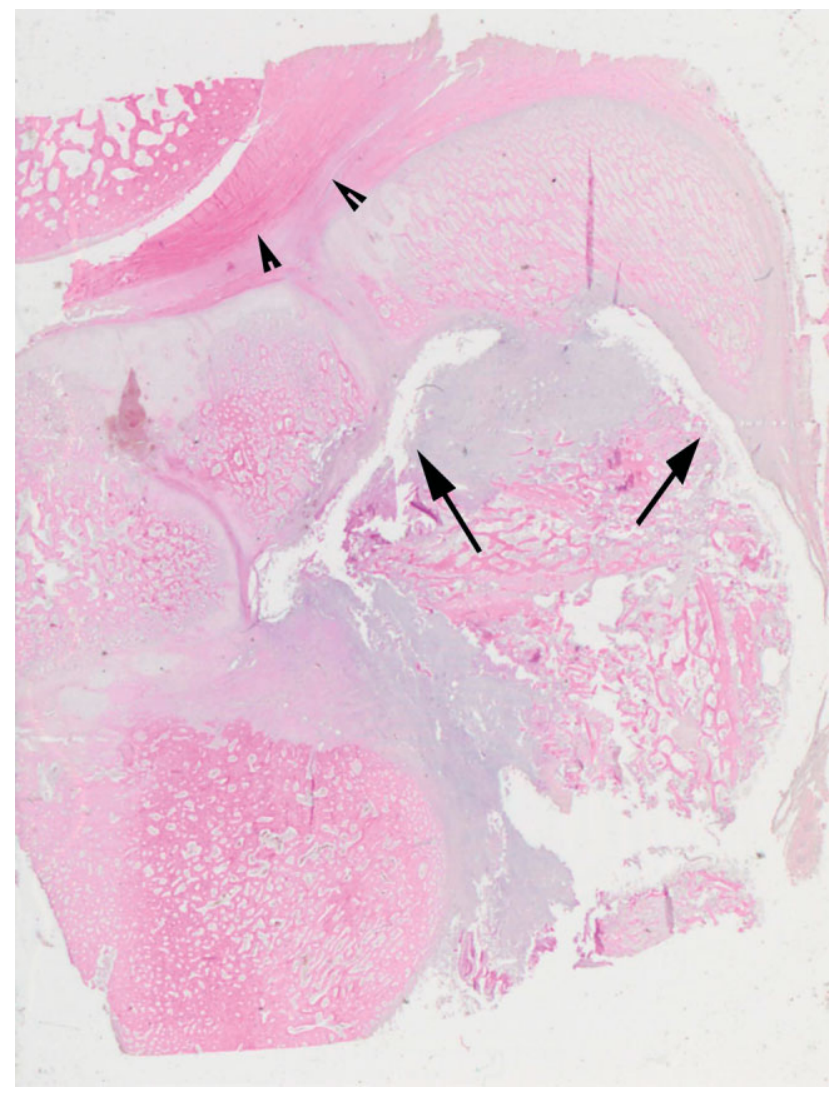

Figure 12. H\&E-stained sagittal section of treatment group. Scaffold is a void depicted by arrows. Exuberant bone tissue with normal architecture exists external to scaffold. Temporomandibular disc relationship is maintained (arrowheads)

CT and MRI clinical imaging modalities. Second, imagebased design techniques allow the creation of multiple datasets at different resolutions. This makes it possible to design the external anatomical shape of the scaffold from a patient image on a centimetre scale, and the scaffold porous architecture based on mechanical and mass transport requirements on a sub- $\mu \mathrm{m}$ scale. The major limitation is computer memory, becoming more readily available all the time, and the scale at which biomaterials can be fabricated $(14,21)$.

There are a number of discrete advantages of SLS in comparison to the other forms of SFF and conventional fabrication techniques. Complex geometries can be manufactured using the layered technique, due to the ability of the laser to access the internal structures in a step-wise fashion. With this method, the surrounding loose powder supports the sintered scaffold, allowing for the creation of overhangs and rapidly changing crosssections. The desired scaffold design is gradually created, and can be removed en bloc from the surrounding loose powder once complete (9).

Micro-CT is well known to be a non-invasive, nondestructive technique which enables one to both analyse and quantify scaffolds pre-operatively and regenerated tissues post-surgically (56). The materials and specimens can therefore be used for future destructive analysis, including histology. More specifically, micro-CT can evaluate scaffold design, architecture continuity and connectivity, bone volume, anisotropy, tissue mineral density and content (31,38,56-59) and, most recently, cartilaginous tissues can be identified (60). For cartilage analysis, the specimen must be directly subjected to ionic contrast (Hexabrix 320, Mallinckrodt, Hazelwood, MO, USA), which binds to sulphated glycosaminoglycans (sGAGs), and determines the density of sGAGs based on
A

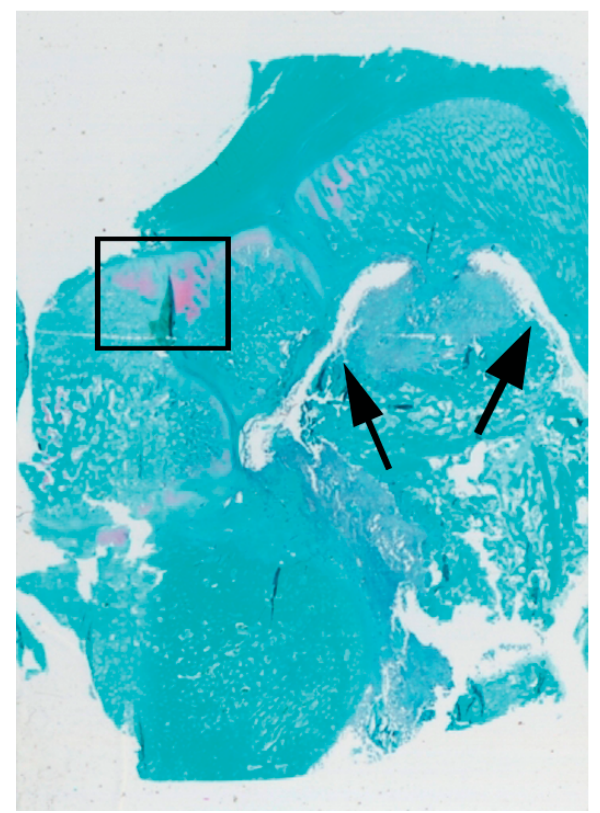

B

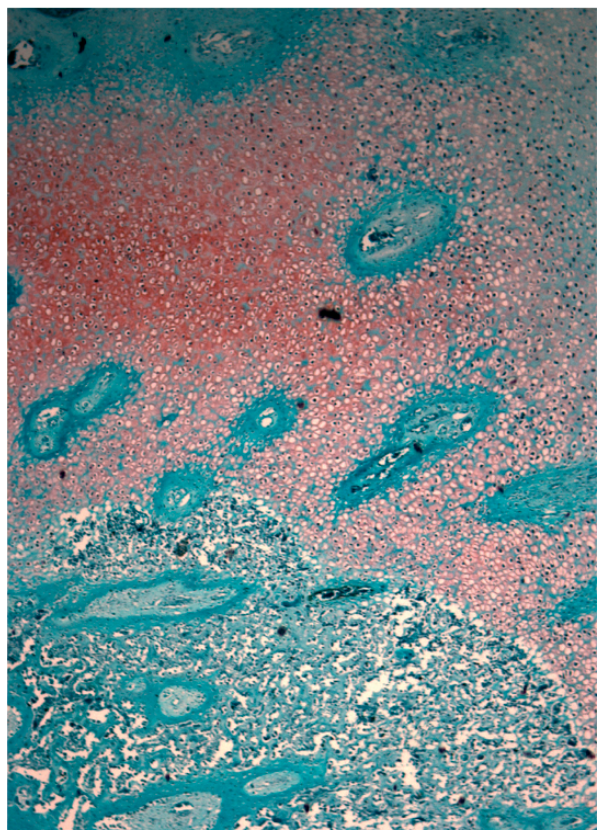

Figure 13. (A) Cartilaginous tissue formation can be identified with safranin $O$ staining. Scaffold void highlighted by arrows. Inset (B) demonstrates normal architecture of the regenerated cartilage 
attenuation. Following this method, the contrast agent can be easily desorbed from the tissue, making the specimens available for histological analysis (60).

Maxillofacial surgeons have a very difficult time attempting to reconstruct osseous tissues to recapitulate facial esthetics. The TMJ proves to be one of the most difficult structures to reconstruct, due to its complex geometrical shape and mechanical function, the presence of both osseous and cartilaginous tissues in close proximity to a fibrocartilagenous disc, and risk of ankylosis (2). Given the demonstrated growth potential of the TMJ of young Yucatan minipigs, we are currently applying both a shell and an architecture-based CRU into the mandibles of mature minipigs that have restricted growth of their osseous tissues. We are continuing to evaluate and apply various scaffolds fabricated through image-based computer-aided design and SLS techniques in animal models. Tissue engineering is proving to be a potentially beneficial avenue to minimize the need for donor site morbidity and also to aid in promoting the growth of hard and soft tissues.

\section{Acknowledgements}

This research was supported by the National Institutes of Health (NIH DE R01 13608; Bioengineering Research Partnership).

\section{References}

1. MacIntosh RB. The use of autogenous tissues for temporomandibular joint reconstruction. J Oral Maxillofac Surg 2000; 58(1): 63-69.

2. Baird DN, Rea WJ. The temporomandibular joint implant controversy: a review of autogenous/alloplastic materials and their complications. J Nutrit Environ Med 1998; 8(3): 289-300.

3. MacIntosh RB, Henny FA. A spectrum of application of autogenous costochondral grafts. J Maxillofac Surg 1977; 5(4): 257-267.

4. Mercuri LG. Total joint reconstruction-autologous or alloplastic. Oral Maxillofac Surg Clin N Am 2006; 18: 399-410.

5. Dodson TB, Bays RA, Pfeffle RC, Barrow DL. Cranial bone graft to reconstruct the mandibular condyle in Macaca mulatta. $J$ Oral Maxillofac Surg 1997; 55(3): 260-267.

6. Mastrogiacomo M, Muraglia A, Komlev V, et al. Tissue engineering of bone: search for a better scaffold. Orthodont Craniofac Res 2005; 8(4): 277-284.

7. Spagnoli DB, Gollehon SG. Distraction osteogenesis in reconstruction of the mandible and temporomandibular joint. Oral Maxillofac Surg Clin N Am 2006; 18: 383-398.

8. Suhr MA, Kreusch T. Technical considerations in distraction osteogenesis. Int J Oral Maxillofac Surg 2004; 33(1): 89-94.

9. Partee B, Hollister SJ, Das S. Selective laser sintering process optimization for layered manufacturing of CAPA(R) 6501 polycaprolactone bone tissue engineering scaffolds. J Manufact Sci Eng 2006; 128: 531-540.

10. Mercuri LG. Subjective and objective outcomes in patients reconstructed with a custom-fitted alloplastic temporomandibular joint prosthesis. J Oral Maxillofac Surg 1999; 57(12): 1427-1430.

11. Mercuri LG, Anspach WE III. Principles for the revision of total alloplastic TMJ prostheses. Int J Oral Maxillofac Surg 2003; 32(4): 353-359.

12. Hollister SJ, Lin CY, Saito E, et al. Engineering craniofacial scaffolds. Orthodont Craniofac Res 2005; 8(3): 162-173.

13. Bonassar LJ, Vacanti CA. Tissue engineering: the first decade and beyond. J Cell Biochem Suppl 1998; 30-31: 297-303.
14. Hollister SJ, Maddox RD, Taboas JM. Optimal design and fabrication of scaffolds to mimic tissue properties and satisfy biological constraints. Biomaterials 2002; 23(20): 4095-4103.

15. Hutmacher DW, Teoh SH, Zein I, Ranawake M, Lau S. Tissue engineering research: the engineer's role. Med Device Technol 2000; 11(1): 33-39.

16. Karageorgiou V, Kaplan D. Porosity of 3D biomaterial scaffolds and osteogenesis. Biomaterials 2005; 26(27): 5474-5491.

17. Schek RM, Wilke EN, Hollister SJ, Krebsbach PH. Combined use of designed scaffolds and adenoviral gene therapy for skeletal tissue engineering. Biomaterials 2006; 27(7): 1160-1166.

18. Langer R, Tirrell DA. Designing materials for biology and medicine. Nature 2004; 428(6982): 487-492.

19. Williams JM, Adewunmi A, Schek RM, et al. Bone tissue engineering using polycaprolactone scaffolds fabricated via selective laser sintering. Biomaterials 2005; 26(23): 4817-4827.

20. Feinberg SE, Hollister SJ, Halloran JW, Gabe Chu TM, Krebsbach PH. A tissue engineering approach to site specific reconstruction of skeletal structures of the maxillofacial region: part II. Shanghai Kou Qiang Yi Xue 2000; 9(2): 88-93.

21. Hollister SJ, Levy RA, Chu TM, Halloran JW, Feinberg SE. An image-based approach for designing and manufacturing craniofacial scaffolds. Int J Oral Maxillofac Surg 2000; 29(1): 67-71.

22. Hollister SJ, Lin CY, Lin CY, et al. Design and fabrication of scaffolds for anatomical bone reconstruction. Med $J$ Malaysia 2004; 59(suppl B): 131-132.

23. McGurk M, Amis AA, Potamianos P, Goodger NM. Rapid prototyping techniques for anatomical modelling in medicine. Ann R Coll Surg Engl 1997; 79(3): 169-174.

24. Berry E, Brown JM, Connell M, et al. Preliminary experience with medical applications of rapid prototyping by selective laser sintering. Med Eng Phys 1997; 19(1): 90-96.

25. Hollister SJ. Porous scaffold design for tissue engineering. Nat Mater 2005; 4(7): 518-524.

26. Fang Z, Starly B, Sun W. Computer-aided characterization for effective mechanical properties of porous tissue scaffolds. Comput Aided Design 2005; 37: 65-72.

27. Lin CY, Kikuchi N, Hollister SJ. A novel method for biomaterial scaffold internal architecture design to match bone elastic properties with desired porosity. $J$ Biomech 2004; 37(5): 623-636.

28. Wettergreen MA, Bucklen BS, Starly B, et al. Creation of a unit block library of architectures for use in assembled scaffold engineering. Comput Aided Design 2005; 37: 1141-1149.

29. Hollister SJ, Zysset PK, Guldberg RE, Chu TM, Halloran JW. Engineering microstructures to evaluate and replace trabecular bone. Adv Exp Med Biol 2001; 496: 199-211.

30. Cooke MN, Fisher JP, Dean D, Rimnac C, Mikos AG. Use of stereolithography to manufacture critical-sized 3D biodegradable scaffolds for bone ingrowth. J Biomed Mater Res B Appl Biomater 2003; 64B(2): 65-69.

31. Darling AL, Sun W. 3D microtomographic characterization of precision extruded poly- $\varepsilon$-caprolactone scaffolds. J Biomed Mater Res B Appl Biomater 2004; 70(2): 311-317.

32. Fisher JP, Holland TA, Dean D, Engel PS, Mikos AG. Synthesis and properties of photocross-linked poly(propylene fumarate) scaffolds. J Biomater Sci Polym Ed 2001; 12(6): 673-687.

33. Porter BD, Oldham JB, He SL, et al. Mechanical properties of a biodegradable bone regeneration scaffold. J Biomech Eng 2000; 122(3): 286-288.

34. Rohner D, Hutmacher DW, Cheng TK, Oberholzer M, Hammer B. In vivo efficacy of bone-marrow-coated polycaprolactone scaffolds for the reconstruction of orbital defects in the pig. $J$ Biomed Mater Res B Appl Biomater 2003; 66(2): 574-580.

35. Rubin JP, Yaremchuk MJ. Complications and toxicities of implantable biomaterials used in facial reconstructive and aesthetic surgery: a comprehensive review of the literature. Plast Reconstr Surg 1997; 100(5): 1336-1353.

36. Sun H, Mei L, Song C, Cui X, Wang P. The in vivo degradation, absorption and excretion of PCL-based implants. Biomaterials 2006; 27(9): 1735-1740.

37. Taylor MS, Daniels AU, Andriano KP, Heller J. Six bioabsorbable polymers: in vitro acute toxicity of accumulated degradation products. J Appl Biomater 1994; 5(2): 151-157.

38. Lin AS, Barrows TH, Cartmell SH, Guldberg RE. Microarchitectural and mechanical characterization of oriented porous polymer scaffolds. Biomaterials 2003; 24(3): 481-489. 
39. Chu TM, Halloran JW, Hollister SJ, Feinberg SE. Hydroxyapatite implants with designed internal architecture. J Mater Sci Mater Med 2001; 12(6): 471-478.

40. Causa F, Netti PA, Ambrosio L, et al. Poly- $\varepsilon$-caprolactone/ hydroxyapatite composites for bone regeneration: in vitro characterization and human osteoblast response. J Biomed Mater Res A 2006; 76(1): 151-162.

41. Gross KA, Rodriguez-Lorenzo LM. Biodegradable composite scaffolds with an interconnected spherical network for bone tissue engineering. Biomaterials 2004; 25(20): 4955-4962.

42. Lin CY, Schek RM, Mistry AS, et al. Functional bone engineering using ex vivo gene therapy and topology-optimized, biodegradable polymer composite scaffolds. Tissue Eng 2005; 11(9-10): 1589-1598.

43. Oldham JB, Lu L, Zhu X, et al. Biological activity of rhBMP-2 released from PLGA microspheres. J Biomech Eng 2000; 122(3): 289-292.

44. Schek RM, Hollister SJ, Krebsbach PH. Delivery and protection of adenoviruses using biocompatible hydrogels for localized gene therapy. Mol Ther 2004; 9(1): 130-138.

45. Schek RM, Taboas JM, Hollister SJ, Krebsbach PH. Tissue engineering osteochondral implants for temporomandibular joint repair. Orthodont Craniofac Res 2005; 8(4): 313-319.

46. Schek RM, Taboas JM, Segvich SJ, Hollister SJ, Krebsbach PH. Engineered osteochondral grafts using biphasic composite solid free-form fabricated scaffolds. Tissue Eng 2004; 10(9-10): 1376-1385.

47. Hutmacher DW. Scaffold design and fabrication technologies for engineering tissues - state of the art and future perspectives. $J$ Biomater Sci Polym Ed 2001; 12(1): 107-124.

48. Tsang VL, Bhatia SN. Three-dimensional tissue fabrication. Adv Drug Deliv Rev 2004; 56(11): 1635-1647.

49. Hutmacher DW, Schantz T, Zein I, et al. Mechanical properties and cell cultural response of polycaprolactone scaffolds designed and fabricated via fused deposition modelling. $J$ Biomed Mater Res 2001; 55(2): 203-216.

50. Lee M, Dunn JC, Wu BM. Scaffold fabrication by indirect threedimensional printing. Biomaterials 2005; 26(20): 4281-4289.
51. Taboas JM, Maddox RD, Krebsbach $\mathrm{PH}$, Hollister SJ. Indirect solid free form fabrication of local and global porous, biomimetic and composite 3D polymer-ceramic scaffolds. Biomaterials 2003; 24(1): 181-194.

52. Properties and Processing of CAPA ${ }^{\circledR}$ Thermoplastics, April 2001; Solvay Caprolactones: Warrington, UK.

53. Das S, Adewunmi A, Williams JM, et al. Mechanical and structural properties of polycaprolactone scaffolds made by selective laser sintering. Proceedings of the 7th World Biomaterials Congress, Sydney, 2004.

54. Naing MW, Chua CK, Leong KF, Wang Y. Fabrication of customized scaffolds using computer-aided design and rapid prototyping techniques. Rapid Prototyping $J$ 2005; 11(4): 249-259.

55. Feldkamp LA, Goldstein SA, Parfitt AM, Jesion G, Kleerekoper M. The direct examination of three-dimensional bone architecture in vitro by computed tomography. J Bone Miner Res 1989; 4(1): $3-11$.

56. Ruegsegger P, Koller B, Muller R. A microtomographic system for the nondestructive evaluation of bone architecture. Calcif Tissue Int 1996; 58(1): 24-29.

57. Ho ST, Hutmacher DW. A comparison of micro CT with other techniques used in the characterization of scaffolds. Biomaterials 2006; 27(8): 1362-1376.

58. Rajagopalan S, Lu L, Yaszemski MJ, Robb RA. Optimal segmentation of microcomputed tomographic images of porous tissue-engineering scaffolds. J Biomed Mater Res A 2005; 75(4): 877-887.

59. Boyd SK, Moser S, Kuhn M, et al. Evaluation of threedimensional image registration methodologies for in vivo micro-computed tomography. Ann Biomed Eng 2006; 34(10): 1587-1599.

60. Palmer AW, Guldberg RE, Levenston ME. Analysis of cartilage matrix fixed charge density and three-dimensional morphology via contrast-enhanced microcomputed tomography. Proc Natl Acad Sci USA 2006; 103(51): 19255-19260. 